\title{
Online content responsiveness strategies in the hospitality context: exploratory insights and a research agenda
}

\author{
Maria Vincenza Ciasullo and Raffaella Montera \\ Department of Management and Innovation Systems, University of Salerno, \\ Fisciano, Italy, and \\ Rocco Palumbo \\ Department of Management and Law, University of Rome Tor Vergata, Rome, Italy
}

Online content responsiveness strategies in hospitality

\begin{abstract}
Purpose - The article investigates different types of strategies for managing user-generated content (UGC) and provides some insights into their implications.

Design/methodology/approach - A unique sample of Italian hotels with current and prospective customers in the digital environment is investigated. A taxonomy of user-provider interactions mediated by UGC is developed. A mixed approach was designed to meet the study aims. Firstly, an exploratory factor analysis was performed in order to illuminate different strategies of UGC and electronic word-of-mouth (E-WOM) management. Secondly, a cluster analysis was implemented in order to explain hoteliers' behavior toward users' contents.

Findings - The study results suggested the existence of three clusters, which reflected three different types of interactions between hotels and customers in the digital domain. Interestingly, most of Italian hotels were found to adopt a reductionist approach to UGC and E-WOM management, turning out to be ineffective to exploit them for the purpose of quality improvement and hospitality service excellence.

Research limitations/implications - Hotels were found to be largely unaware of the importance of UGC and web-based communication with customers to improve their digital business strategy. Tailored management approaches are needed to realize the full potential of hotels' online content responsiveness for the purpose of value co-creation and service co-production.

Originality/value - This is one of the first studies investigating the strategic and management perspectives embraced by hotels to handle their interactions with customers in the digital arena.
\end{abstract}

Keywords Hospitality, UGCs, E-WOM, ICTs, Value co-creation

Paper type Research paper

\section{Introduction}

Information and communication technologies (ICTs) dramatically changed consumer behaviors. Digitalization transformed the way people search for products and services, obtain information, evaluate alternatives and make purchase decisions. The spread of usergenerated content (UGC) - especially in the form of reviews - further contributed in this process. Missing first-person experiences, consumers rely on others' insights to compare products and services (Flanagin and Metzger, 2013). Reviews are a major source of electronic word-of-mouth (e-WOM), reducing information asymmetry for prospective consumers ( $\mathrm{Li}$ et al., 2017). The influence of online information on consumer behaviors seems to be more relevant for services than for goods, due to their intangible nature (Christodoulides et al., 2012). Tourism and hospitality services, whose experiential nature involves subjective evaluations

(C) Maria Vincenza Ciasullo, Raffaella Montera and Rocco Palumbo. Published by Emerald Publishing Limited. This article is published under the Creative Commons Attribution (CC BY 4.0) licence. Anyone may reproduce, distribute, translate and create derivative works of this article (for both commercial and non-commercial purposes), subject to full attribution to the original publication and authors. The full terms of this licence may be seen at http://creativecommons.org/licences/by/4.0/legalcode

Received 22 December 2019 Revised 8 March 2020 Accepted 18 March 2020 
and prevents the assessment of service quality before consumption, are especially affected by e-WOM (Litvin et al., 2008; Li et al., 2017). A recent study underlines that 53\% of online purchases in the European Union include travel and holiday accommodation (Eurostat, 2017). Travelers are increasingly willing to use websites hosting reviews to make informed decisions (Kwok et al., 2017). However, scholars maintain that tourism firms are unwilling to use webbased technologies as a part of their business strategy (Burgess et al., 2015; Lui et al., 2018). They generally use the Internet as a distribution channel for promotional purposes, rather than as a tool to better understand customers' needs and expectations.

As Kwok et al. (2017) claim, e-WOM has been largely analyzed from the customers' point of view. Attention has been primarily focused on the effects of online ratings on consumers' decision-making, satisfaction, and loyalty. There is an increasing research interest in examining the implications of the online reviews on business performance (Duverger, 2013; Xie et al., 2014; You et al., 2015; Phillips et al., 2017; Viglia and Buhalis, 2016). To the best of the authors' knowledge, few studies deal with managerial postures and capabilities related to potential antecedents and consequences to exploit digital channels (Assimakopoulos et al., 2014; Abramova et al., 2015).

In an attempt to fill the existing gap in the scientific knowledge, this study focused on how hotel managers handle e-WOM. On the one hand, the usage of different web-based tools was investigated. On the other hand, the objectives and the practices according to which hotel managers collect, manage and monitor UGC were examined. Lastly, the role of hotel manager in improving the value of UGC was discussed. In sum, the study intends to answer the following research questions:

$R Q 1$. How do hotels integrate UGC in their business?

$R Q 2$. How do hotels manage e-WOM?

An empirical study was designed involving a unique sample of Italian hotels. The focus on the Italian context was motivated by two factors. Firstly, Italian hotels primarily consist of smallsized family firms that are not affiliated to multinational chains and, consequently, are unable to rely on international strategies for managing e-WOM. Secondly, Italy is an internationally relevant tourist destination: according to the World Travel and Tourism Council, Italy is the sixth world country in terms of tourism contribution to GDP $(13 \%)$ (WTTC, 2018).

The article is organized as follows. Section 2 underpins the theoretical concepts of e-WOM in the hospitality context. Research design and methods are reported in Section 3. Next, Section 4 presents the findings, which are discussed in Section 5. Ex post propositions are suggested in Section 6 in order to trigger future researches on e-WOM strategic management. Section 7 ends up the paper, acknowledging the study limitations.

\section{Literature review}

\subsection{Defining e-WOM in the hospitality context}

Communication and social interaction technologies allow customers to decide the way they receive, respond and share information, modifying how they interact with companies. The Internet is a user-driven repository of information and relationships. Therefore, it demands transformation in the modes companies manage their relationship with users. UGC have been proven to be more influential than corporate-led communications in affecting customers' decisions due to their independence from commercial influence. In particular, e-WOM has been considered one of the most influential UCG tool for purchase decisions (Bore et al., 2017).

E-WOM is an informal type of online communication. It is much more influential than WOM, since it offers greater convenience, anonymity, many-to-many communication and no restrictions in terms of time and space (Xu and Li, 2015; Tsao et al., 2015). The impact of eWOM is especially salient when it comes to service products, including tourism and 
hospitality. Analyzing the tourist behaviors, scholars underline that online reviews are considered the most important forms of e-WOM to book a hotel and to indirectly experience the service (Gu and Ye, 2014; Hu and Kim, 2018). E-WOM's spread has been facilitated by the growth of websites, such as hotel institutional web-pages, online travel agencies (OTA) and third-party hotel review websites. The emergence of new forms of online communication such as social media networks - has further contributed to increase the power of e-WOM(Yoo and Gretzel, 2011). Facebook, Twitter, YouTube and Flickr represent open and collaborative environments in which users may collect insights from any form of media, ranging from picture/video, wikis, blogs, recommendations, rating, fora and message boards.

Several studies have been carried out to identify the factors motivating customers to write online review and produce e-WOM. Marketer-generated sites are usually used for self-directed interests, providing planning functionality and opportunity to review tourism destinations and related services. Conversely, consumer-generated channels tend to be used for otherdirected interests, such as advocacy, helping other travelers and vacationers or company and gaining social benefits. In this stream of research, some factors emerged as leading to e-WOM, such as satisfaction, commitment, social identity, pre-purchase expectations (Crotts et al., 2009), sense of community belonging, gender and age (Sun and Qu, 2011; Nusair et al., 2011). E-WOM has been also discussed as an important factor affecting the consumer decision-making process (Litvin et al., 2008; Xie et al., 2011), online consumer buying decisions and purchase intentions (Ye et al., 2009), loyalty (Baka, 2016), product acceptance, brand awareness and risk reduction (Kim et al., 2011; Sparks and Browning, 2011).

Ratings published by well-known online travel communities are deemed useful and credible, triggering positive or negative attitudes toward a hotel Casaló et al., 2015). Both number (volume) and degree of positivity (valence) of online reviews have been proven to matter, being a signal of hotel popularity and customer preference, which may determine a normative behavior ("go with the crowd") (Kwok et al., 2017). Purchase intention can be damaged if negative valence of reviews prevails, because negative comments can give credence to the entirety of the reviews, harming the hotel reputation (Liang et al., 2013). A literature review on online reviews in tourism and hospitality recently disclosed two main research priorities: (1) assessing the impact of online reviews on guests' buying behavior, and (2) understanding how hospitality businesses should manage online reviews (Schuckert et al., 2015).

Whilst the scholars have largely investigated the effects of e-WOM on the first research stream, management strategies and their effectiveness are under-researched (Nguyen and Coudounaris, 2015; Schuckert et al., 2015). Studies adopting a provider perspective are mainly focused on analysing the economic impact of e-WOM on hotel performance in terms of sales (Ye et al., 2009) and financial performance (Xie et al., 2014; Phillips et al., 2017; Raguseo and Vitari, 2017). Recently, De Pelsmacker et al. (2018) emphasized the importance for hotel management of devoting considerable attention to UGC, analysing the effects of marketing decisions on room occupancy and revenue per available room (RevPAR) mediated by volume and valence of online reviews.

\subsection{Managerial approaches to $e$-WOM}

E-WOM management is crucial to enhance and increase the hotels' competitiveness: it represents the outcome of an integrated process in which information and interactions represent drivers and enablers. As a driver, e-WOM stimulates hospitality managers to engage in enriching market intelligence and generate information. Such information can be managed to identify hotels' strengths and weaknesses, the service elements that customers consider more relevant, the competitive gaps that need to be filled in order to improve services and to benchmark the competitors' online reputation (Litvin et al., 2008; Burgess et al., 2015; Aureli and Supino, 2017). This information can be also used to support decision-making by providing new service development and better segmentation (Sigala et al., 2012), adapting
Online content responsiveness strategies in hospitality

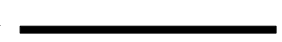


pricing strategy and sustaining more informative choices based on data monitoring (Levy et al.,2013). As an enabler, e-WOM allows hospitality managers to build dynamic interactions based on interactive communication flows with customers (Cantallops and Salvi, 2014). This implies boosting guests to become involved in the online discussions, encouraging them to post comments, responding to guest complaints in order to demonstrate attention to service failure and customers' concerns and provide re-assurance.

A corporate integrated reputation system is needed to analyze customers' feedback on the company's website and manage customer reviews from popular online travel communities. Adding hyperlinks to and integrating third-party reviews on the corporate website, or utilizing private channels such as WhatsApp, Facebook Messenger, Twitter Direct Message or email newsletters enable data mining and generate real-time information, facilitating customer-company interactions. Scholars who investigated the influence of social media on internal and external operations found that travelers exposed to a hotel website embedding social media channels have higher levels of perceived informativeness, enjoyment, social interaction and satisfaction (Aluri et al., 2016). Therefore, hotel managers need a well-defined managerial response approach on when and how to respond to UCG, shifting from passive listening to active engagement through management responses. Online response management as a form of customer relationship management becomes fundamental to providing useful knowledge for service quality improvement and innovation, enhancing the opportunities to customize and personalize service offering ( $\mathrm{Gu}$ and $\mathrm{Ye}, 2014$ ).

Literature has explored the importance of responding to customers' comments. Some scholars highlighted the need for managing effectively the responses through dedicated and skilled human resources, such as general manager, social media manager and specialized third-party companies (Aureli and Supino, 2017). Functional staff/departments, alongside executives, should provide managerial responses, because their operational insights allow them to better address consumer comments. However, empirical evidence is mixed. Some studies find that responses by senior staff are more effective than those by low-position employees (Van Laer and de Ruyter, 2010), whilst others find no differences (Sparks et al., 2016). Nevertheless, scholars are unanimous in arguing that the lower the time taken by a hotel to post an online response to customers' reviews, the higher the effectiveness - as far as human resources are skilled in managing the interaction (Xie et al., 2014; Min et al., 2015; Li et al., 2017; Lui et al., 2018). It has been noted that professional responses are more formal and task-oriented, but limited in affective content. Conversely, conversational responses are more informal and direct, mimicking one-to-one communication (Sparks et al., 2016).

Response contents represent another critical issue for scholars. The content can be defensive or accommodating and can have a narrative or analytical format (Lee and Song, 2010; Lee and Cranage, 2014). A defensive response generally uses justification to deny hotel's responsibility for the problem or excuses to negate it. The accommodative response is used when the firm takes substantial responsibility for the problem and attempts to amend it (Lee and Song, 2010). Defensive responses have been proven to be more effective than accommodating ones for low consensus reviews. However, an accommodating approach paves the way for high consensus (Lee and Cranage, 2014). The content of the response can be tailored to the review by implementing a personalized and specific response addressing or not issues relevant to the particular customer review (Min et al., 2015; Crijns et al., 2017). Both responses targeting prospective consumers and those focusing on complainers are possible (Gu and Ye, 2014; Li et al., 2018). Specific responses have been demonstrated to be more effective than generic ones (Min et al., 2015). The response effectiveness also depends on action frame (time and type) of corrective actions undertaken. Management responses may indicate that the problem highlighted in the online review has already been solved (actions have been taken), or that problem resolution is in progress or that it will be addressed in the future (an action is promised to be taken in the future) (Sparks and Bradley, 2017). Moreover, 
hotels can provide financial compensations and corrective remedies, such as refunds or replacements, to answer consumers' concerns.

Despite the potential value offered by response features, there is little research focusing on response management strategies in the hotel setting (Abramova et al., 2015; Liu et al., 2015; Lui et al., 2018), and few studies empirically classify them in terms of effectiveness for hotel marketers (Rose and Blodgett, 2016). From this point of view, the study differs from previous research on management response in two aspects. First, it conceptualizes strategies for managing UGC in a comprehensive way as the capability of exploiting the opportunities offered by the Internet. Second, the investigation of the different types of tactics for managing UGC allows the identification of the main effects of responding. In sum, antecedents and consequences on UCG have been addressed, whilst most research on hotel responses to eWOM is confined to hoteliers' online responses (Bore et al., 2017).

\section{Research method}

\subsection{Sample}

Population size $(N)$ comprised 4,986 Italian hotels indexed by the Aida-Bureau Van Dijk database. Sample size $(n)$ was calculated using the formula for finite population. It was considered satisfactory to set a $95 \%$ confidence level (standard value $=1.96$ ). A SD target of 0.5 was set according to a pilot survey conducted on a small number of units. A sample consisting of 536 units was considered to be sufficiently large and representative. A simple random sampling approach was used to identify the units of analysis.

\subsection{Data collection}

An online survey was used to collect data. Hotels were invited by e-mail to take part in the survey in October 2018. The involvement of owners, general managers, social media managers, community managers and digital marketing managers was required. The questionnaire consisted of four sections and 31 closed-ended questions with a 5-point Likert scale (see Appendix for details). Section 1 briefly described the survey purpose; use of data and confidentiality statement were also included. Section 2 comprised six questions on the hotel profile in terms of location, category and ownership type; besides, it included some items intended to identify the organizational roles in charge of digital marketing function. Section 3 contained eight questions on hoteliers' commitment toward digital channels and relative applications of UGC. Lastly, Section 4 included 17 questions on the e-WOM consideration, strategic and operative features of hotel responses and effects of responding. Respondents indicated their perceived degree of adoption of the practice described in the item $(1=$ never; $5=$ always $)$ or the agreement with the statement reported $(1=$ strongly disagree; 5 = strongly agree). Before the formal survey on full-scale, a pilot test was conducted involving a convenience sample of 20 executives to identify problems to be addressed prior to putting the survey in the field (Lavrakas, 2008). The pilot test's feedback was used to assess the response latency (Draisma and Dijkstra, 2004) and ensure the correct use and understanding of the questions in the context of hotel businesses.

\subsection{Data analysis}

3.3.1 Measures. A literature review focusing on UGC management and e-WOM in hotel setting was performed to develop the measurement items. Some existing scale items validated in previous studies have been adopted. Furthermore, some existing scale items have been modified and adapted, and new items have been developed. A pre-test was conducted with three academics in digital marketing field and four hotel managers to obtain suggestions and feedback on the identified measurement items (Dillman, 2011). Criteria used to select academics were $\mathrm{PhD}$ in the digital marketing field and articles in digital marketing published in reference journals. Hotel managers were selected considering at least five years 
of work experience and a practitioner expertise recognized by managerial awards. Once the pre-test was completed, revisions were made by removing five items considered irrelevant and lengthy [1]. Hence, 25 scale items remained; they were grouped into 6 dimensions (see Table 1).

3.3.2 Exploratory factor analysis (EFA). This research applied EFA to identify the factors that contributed to explain the hoteliers' behavior toward UCG and e-WOM. EFA is a multivariate statistical method that is appropriate for understanding the dimensionality of a set of variables and for isolating variables that do not effectively represent the dimensions (Osborne et al., 2008). Through EFA, the smallest number of latent dimensions or variables can be identified from within the measurement scales by grouping individual items into a limited set of clusters based on shared variance (Yong and Pearce, 2013). Items that are grouped together are presumed to be measuring the same underlying construct (Kerlinger, 1986).

To determine the latent factors associated with the 25 items reported in Table 1, EFA was performed using SPSS v24. Comparing numerous extraction methods, the most interpretable solution was derived using principal components analysis (PCA) as an extraction method (Tabachnick et al., 2007) and Promax as rotation procedure (Abdi, 2003). Kaiser's (1970) eigenvalue rule (retention of factors with eigenvalues greater than one) was used to extract the components. The 25 scale items initially loaded on to 14 factors with eigenvalues greater than one, accounting for $70.5 \%$ of the explained variance. However, some factors were oneitem solutions. Next, scree test - that invokes a maximum number of factors - was conducted to produce a more interpretable solution (Cattell, 1965) based on a total of four factors. The factor analysis was re-run with this criterion that accounted for $63 \%$ of the explained variance. However, scree test is fundamentally subjective and can lead to spurious solutions (Zwick and Velicer, 1986). Thus, to further verify the suitable number of factors to be retained, a parallel analysis was performed (Horn, 1965): three factors were found to be logically consonant for the factor analysis. Measure of sampling adequacy and significance of the Bartlett's test of sphericity suggested that the correlation matrices were representative identity matrices suitable for multivariate analysis. Moreover, parallel analysis is acknowledged as the most reliable alternative to identify the quantity of underlying latent variables (Zwick and Velicer, 1986).

3.3.3 Cluster analysis. A cluster analysis was performed to improve the analysis's depth by developing more interpretable and clearly discriminated classes of hotels. It is a set of multivariate techniques aimed to group objects (e.g. respondents, products or other entities) based on their characteristics (Hair et al., 1998). Factorial scores were used as input data. More specifically, the k-means method was selected for clustering: it produces $k$ different clusters of greatest possible distinction by starting with $k$ random clusters, and then moving objects between those clusters to minimize variability within clusters and maximize variability between clusters (Sharma, 1996). Since we were interested in investigating the online responsiveness of units of analysis regardless of their organizational size, we did not contemplate the hotels' dimension in performing our cluster analysis.

\section{Findings}

On the whole, 220 hotels responded to the survey. However, 34 surveys were discarded due to missing data. Therefore, 186 useable surveys entered the analysis stage: this yielded an effective response rate of $41 \%$.

\subsection{EFA findings}

EFA generated three factors with eigenvalue greater than one. Table 2 shows the factorial model and the loading. Both the Bartlett sphericity test $(0.000<0.001, \mathrm{df}=820)$ and the KMO 


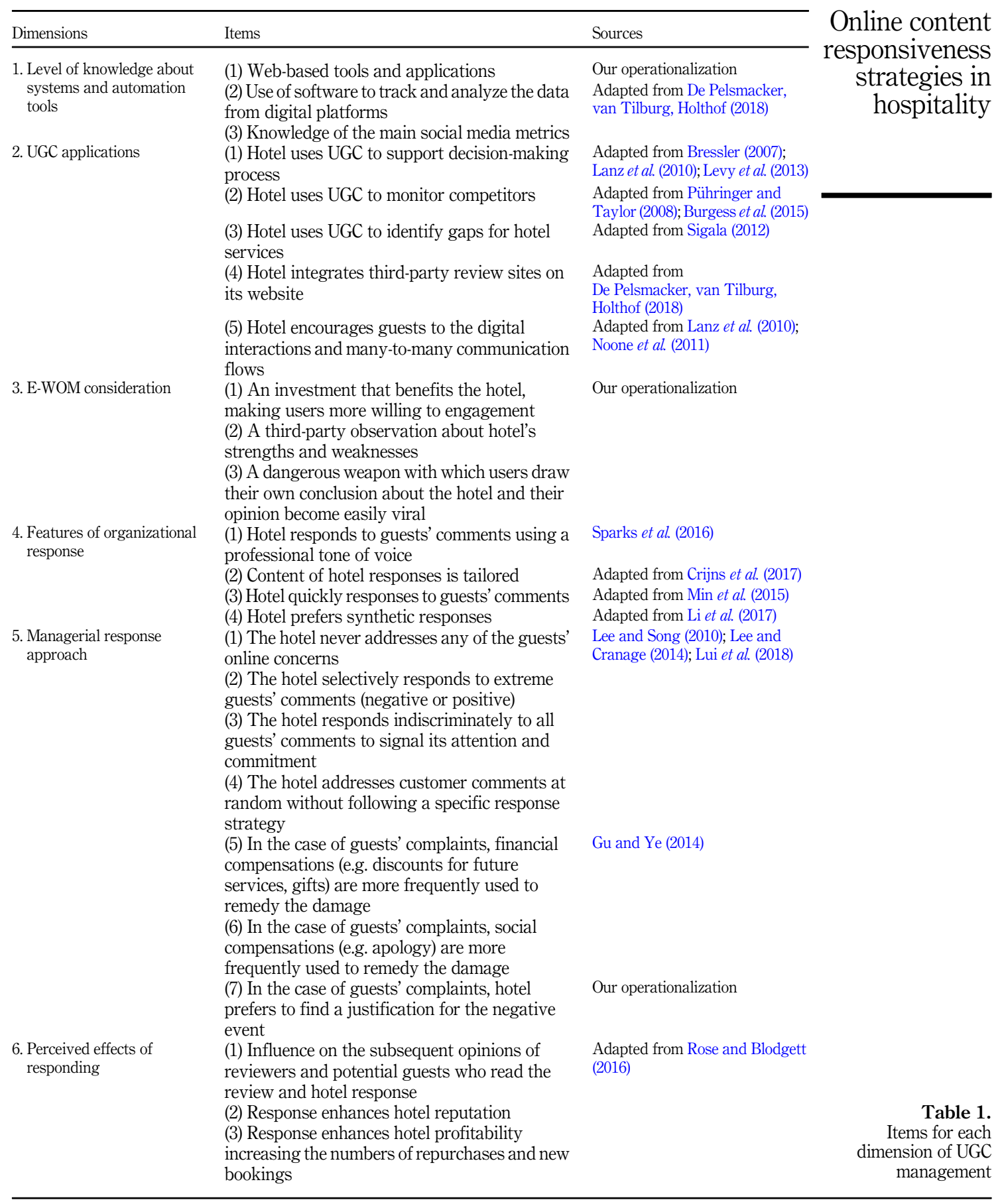




\begin{tabular}{|c|c|c|c|}
\hline & 1 & 2 & 3 \\
\hline $\begin{array}{l}\text { 3.a) E-WOM as investment that benefits the hotel, making users more willing to } \\
\text { engagement }\end{array}$ & 0.699 & 0.111 & $*$ \\
\hline $\begin{array}{l}\text { 2.e) Hotel encourages guests to the digital interactions and many-to-many } \\
\text { communication flows }\end{array}$ & 0.696 & 0.139 & 0.211 \\
\hline 5.b) The hotel selectively responds to extreme guests' comments (negative or positive) & 0.690 & * & 0.164 \\
\hline Hotel uses UGC & 0.688 & $*$ & 0.144 \\
\hline $\begin{array}{l}\text { 6.a) Influence on the subsequent opinions of reviewers and potential guests who read } \\
\text { the review and hotel response }\end{array}$ & 0.686 & 0.104 & * \\
\hline 4.b) Content of hotel responses is tailored & 0.683 & . & 0.282 \\
\hline view sites on its website & 0.677 & 0.170 & 0.245 \\
\hline l.b) Use of software to track and analyze the data from digit & 0.672 & & 0.306 \\
\hline 6.b) Resp & 0.669 & 0.307 & \\
\hline 1.a) Web-b & 0.662 & 0.274 & 0.133 \\
\hline $\begin{array}{l}\text { 5.f) In the case of guests' complaints, social compensations (e.g. apology) are more } \\
\text { frequently used to remedy the damage }\end{array}$ & 0.656 & 0.145 & 0.167 \\
\hline $\begin{array}{l}\text { 5.c) Hotel responds indiscriminately to all guests' comments to signal its attention and } \\
\text { commitment }\end{array}$ & 0.279 & 0.703 & 0.238 \\
\hline $\begin{array}{l}\text { 3.c) E-WOM as dangerous weapon with which users draw their own conclusion about } \\
\text { the hotel and their opinions become easily viral }\end{array}$ & 0.292 & 0.698 & 0.271 \\
\hline $\begin{array}{l}\text { 5.e) In the case of guests' complaints, financial compensations (e.g. discounts for } \\
\text { future services, gifts) are more frequently used to remedy the damage }\end{array}$ & 0.306 & 0.692 & 0.155 \\
\hline 1.c) Knowledge of the mi & 0.215 & 0.688 & * \\
\hline 2.b) Hotel & 0.304 & 0.679 & 0.273 \\
\hline $\begin{array}{l}\text { 6.c) Response enhances hotel profitability, increasing the numbers of repurchases and } \\
\text { new bookings }\end{array}$ & 0.301 & 0.674 & 0.149 \\
\hline 4.a) Hotel responds to guests' comments using a professional tone of voice & 0.141 & 0.667 & 0.132 \\
\hline 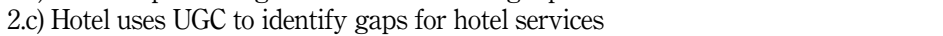 & 0.236 & 0.663 & \\
\hline ts' comments & 0.251 & 0.660 & 0.253 \\
\hline third-party obser & 0.146 & 0.166 & 0.673 \\
\hline $\begin{array}{l}\text { 5.d) The hotel addresses customer comments at random without following a specific } \\
\text { response strategy }\end{array}$ & 0.109 & 0.169 & 0.669 \\
\hline $\begin{array}{l}\text { 5.g) In the case of guests' complaints, hotel prefers to find a justification for the } \\
\text { negative event }\end{array}$ & * & 0.112 & 0.663 \\
\hline 4.d) Hotel prefers synthetic responses & 0.107 & * & 0.658 \\
\hline
\end{tabular}

Table 2.

EFA findings
Note(s): * Item loading of $<0.10$; Item 5 . a is not present in Table 2 because its loadings are $<0.40$ on all factors: 1st factor: $<0.10$; 2nd factor: $<0.10$; 3rd factor: 0.114

sample adequacy measure of 0.781 ( $>$ of 0.50 ) confirmed the appropriateness of the development of a factor analysis (Lattin et al., 2003).

All the variables showed a commonality equal to or greater than 0.50 , suggesting a good overall significance of the analysis which produced a three-factor structure. Cronbach's alpha reliability coefficient for the individual factors was satisfactory (1st factor: 0.75 ; 2 nd factor: 0.77; 3rd factor: 0.76 ). Finally, the total variance explained was $61 \%$. Three dimensions were identified through the interpretation of EFA results, defining hotel responsiveness as the underlying capability in managing UGC. Online content responsiveness reflects the capability of hotel managers to collect intelligence in order to generate valuable knowledge, manage digital interactions to engage users, address their concerns and restore their satisfaction using online review system. That said, the first factor is labeled "proactive online content responsiveness." It explains 38\% of variance and includes the highest number of items referred to an integrate use of digital channels and relative UGCs application, organizational response tools and perceived effects of responding. In this case, online review 
system is used as a mechanism to engage both guests who have already experienced the service, and prospect guests whose centrality is recognized in the offering's creation.

Going over, the second and third factors comprise items referred to managerial response approach, showing hotel efforts in UGC monitoring. Different types of online content responsiveness are involved. The second factor, that explains $18 \%$ of variance, is labeled "reactive online content responsiveness." In this case, despite e-WOM being considered dangerous, the online review system is used to analyze the feedback generated by guests following a service recovery approach. The third factor, that explains $6 \%$ of variance, is labeled "passive online content responsiveness," since it is characterized by lack of awareness of the strategic opportunities deriving from guests' online reviews. This is showed by the high coefficient of item referred to the e-WOM as a third-party observation (0.673) and by the adoption of a random response approach (0.669).

\subsection{Cluster analysis' results}

To infer the correct cluster number, a pseudo- $F$ test (Calinski and Harabasz, 1974) was conducted. Pseudo- $F$ increases up to the three-cluster solution, suggesting the latter as the optimal one. The three-cluster solution yielded $F$-values larger than 58.138 ( $\phi$-values $<0.0000)$. Table 3 shows final centroids and proportions for the three clusters.

Hotels belonging to cluster $1(39.78 \%)$ are characterized by the highest scores on reactive online content responsiveness $(0.860)$. Cluster $2(26.34 \%)$ shows the highest scores on passive online content responsiveness $(0.790)$. Lastly, cluster $3(33.87 \%)$ gathers hotels with the highest scores on proactive online content responsiveness (0.961). To gain further support for the three-cluster solution, a validation procedure was conducted according to Lattin et al. (2003). The sample was split into two subgroups by applying a random selection procedure. Specifically, the calibration sample included about $70 \%$ of hotels, whereas the validation sample encompassed about $30 \%$. Four steps followed. Firstly, a k-means cluster analysis was run on the calibration sample and saved final centroids; the resulting three-cluster solution was substantially identical to the whole sample analysis. Secondly, final centroids from the calibration data were used to classify hotels from the validation sample: this classification was denoted as S1. Thirdly, a k-means cluster analysis was run on the validation sample, and final centroids from such application were used to classify hotels from the validation sample: this classification was denoted as S2. Fourthly, a Rand index of 0.924 was found, showing an agreement between S1 and S2 and suggesting a strong capability of the clustering model. Starting from the table of the cluster membership where each observation is referred to the relative cluster (Table 4), some descriptive variables are presented below to better report the features of three clusters (Table 5).

Cluster 1 is the most numerous, comprising 74 hotels mainly located in Central (39\%) and Northern (35\%) Italy. They are mainly independent hotels (57\%) up to 3 stars $(51 \%)$. Inside their organization, both specific $(45 \%)$ and general $(48 \%)$ roles are in charge of digital

\begin{tabular}{lccc}
\hline & \multicolumn{3}{c}{ Cluster } \\
Dimension & 1 & 2 & 3 \\
\hline \% Proportion & 39.78 & 26.34 & 33.87 \\
Proactive online content responsiveness & 0.464 & -0.121 & 0.961 \\
Reactive online content responsiveness & 0.860 & 0.349 & 0.569 \\
Passive online content responsiveness & -0.163 & 0.790 & 0.149
\end{tabular}

Note(s): Positive scores on one dimension indicate higher than average traits within the clusters. Negative scores on one dimension indicate lower than average traits within the clusters
Online content responsiveness strategies in hospitality 
TQM

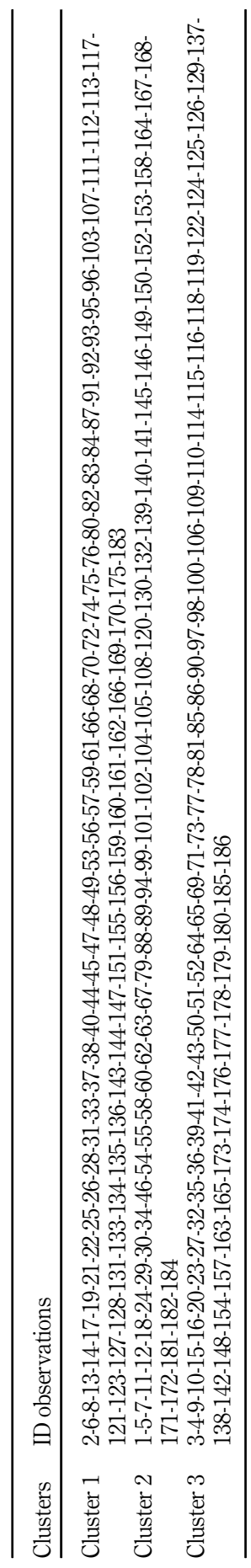

Table 4.

Cluster membership 


\begin{tabular}{|c|c|c|c|c|c|}
\hline \multicolumn{2}{|l|}{ Descriptive variables } & \multirow{2}{*}{ Cluster 1} & \multirow{2}{*}{ Cluster 2} & \multirow{2}{*}{$\frac{\text { Cluster } 3}{44}$} & \multirow{4}{*}{$\begin{array}{r}\text { Online content } \\
\text { responsiveness } \\
\text { strategies in } \\
\text { hospitality }\end{array}$} \\
\hline \multirow[t]{3}{*}{ Geographic location } & Northern Italy & & & & \\
\hline & Central Italy & 39 & 41 & 16 & \\
\hline & Southern Italy* & 26 & 47 & 40 & \\
\hline \multirow[t]{2}{*}{ Category } & Up to 3 stars & 51 & 60 & 45 & \\
\hline & From 4 stars up & 49 & 40 & 55 & \\
\hline \multirow[t]{2}{*}{ Ownership type } & Chains & 43 & 33 & 40 & \\
\hline & Independent & 57 & 67 & 60 & \\
\hline \multirow[t]{3}{*}{ Digital marketing roles } & Specific roles** & 45 & 24 & 63 & \\
\hline & General roles*** & 48 & 71 & 21 & \\
\hline & External providers***** & 7 & 5 & 16 & \\
\hline \multirow[t]{5}{*}{ Digital tools****** } & Online travel agencies & 40 & 38 & 19 & \\
\hline & Third-party review websites & 10 & 7 & 30 & \\
\hline & Hotel websites & 35 & 47 & 100 & \\
\hline & Social media & 11 & 6 & 14 & \\
\hline & Apps & 4 & 2 & 12 & \\
\hline \multirow{4}{*}{ Speed of responses } & Daily & 51 & 13 & 97 & \\
\hline & Weekly & 34 & 68 & 3 & \\
\hline & Monthly & 10 & 12 & - & \\
\hline & Less frequently & 5 & 7 & - & \\
\hline \multicolumn{5}{|c|}{$\begin{array}{l}\text { Note(s): *Islands included; ** Social media manager, community managers, digital marketing manager; } * * * \\
\text { Owner, general manager, sales director; **** Social media consultants; ***** In cluster } 3 \text {, the total value } \\
\text { exceeds } 100 \% \text { because all hotels use corporate websites together with others digital tools }\end{array}$} & $\begin{array}{r}\text { Table } 5 . \\
\text { Clusters' profile (\%) }\end{array}$ \\
\hline
\end{tabular}

marketing and manage digital systems to analyze UGC. In particular, responses are managed on daily basis (51\%). Online travel agencies $(40 \%)$ and corporate websites $(35 \%)$ represent the more used digital tools. A total of 49 hotels, mainly up to 3 stars $(60 \%)$ and independent (67\%), belong to cluster 2 that shows a geographical concentration in Southern Italy $(47 \%)$ and Central Italy (41\%). Digital marketing and online content monitoring are performed by general roles $(71 \%)$ that often use the hotel website among digital tools $(47 \%)$. Responses are managed on weekly basis (68\%). Cluster 3 comprises 63 hotels mainly located in Northern Italy $(44 \%)$ and - probably - in developed touristic destinations of Southern Italy $(40 \%)$. They are mainly independent hotels $(60 \%)$ from 4 stars up $(55 \%)$. Inside their organization, specific roles $(63 \%)$ deal with the digital marketing and online content monitoring, managing responses on daily basis $(97 \%)$ in real time. Hotel website is the digital tool used by entire cluster $(100 \%)$ together with third-party review websites $(30 \%)$, online travel agencies $(19 \%)$, social media $(14 \%)$ and apps $(12 \%)$.

\section{Discussion}

The exploratory factor analysis, followed by a cluster analysis, allowed deepening the knowledge of Italian hoteliers' review management strategies and to shed some light on their implications. In an inter-cluster perspective, research findings highlighted that Italian hotels are aware that digital marketing management plays a critical role in their business strategies. This is confirmed by the fact that almost the entire sample manages the process of UGC monitoring internally. However, Italian hotels show different attitudes that correspond to various types of online content responsiveness. In particular, the study findings highlighted that the majority of hotels (cluster 1) adopted a reactive strategy, implementing a problemsolving approach to manage online contents. This strategy is characterized by a reductionist model, as it exclusively embraces a monitoring attitude toward UGC and a service recovery logic in the online interactions with guests. 
Online contents are utilized as mechanisms for a quick but efficient and discrete resolution of guests' complaints. Managers seem to pay close attention to the rating and ranking provided by the online travel agencies, probably with the aim of analyzing competitors rather than actively involving guests. A more tactical utilization of digital channels is evident in this cluster, as demonstrated by the massive use of online travel websites and the corporate website, and conversely - by the limited use of social media platforms and mobile tools. In other words, these hoteliers are willing to increase their popularity and give online visibility to their offerings, using online travel agency websites. However, they show a limited involvement in managing UGC strategically. In fact, e-travel agencies are used as electronic commerce platform to increase the online bookings. This is also confirmed by the response strategy adopted (Lui et al., 2018). It consists in responding indiscriminately to all guests' comments with a professional style of communication. By increasing the response velocity, hoteliers believe that high speed of responses lead to positive reviews, higher ratings and more helpfulness rankings that improve their online reputation (Sparks et al., 2016; Li et al., 2017). In case of negative opinions, hotels solve any damages through technical recovery actions, proposing financial compensations (i.e. discounts, refunds, etc.) as a contingent attempt to restore customer satisfaction and prevent customer exits. The professional style of communication adopted represents a formal style, that provides standardized - and often generic - responses that are profit-driven and task-oriented (Sparks et al., 2016). Moreover, financial compensations are considered a practice of accommodative response (Lee and Song, 2010; Lee and Cranage, 2014). They are related to a value exchange based on value for money. Nevertheless, customers may be more interested in nonmonetary compensations (i.e. apology, showing care, fairness).

Customer satisfaction is achieved not only in terms of speed of responding and number of responses (volume), but also on quality and effectiveness of responses (valence). In other words, it is how a firm responds to customer complaint that enhances customer satisfaction and loyalty. A variety of responses to customer complaints are emphasized in the cluster of hotels that showed a proactive responsiveness (cluster 3). The integrated use of different digital channels and embedded interactions with users characterized these hotels. A more holistic approach emerges, because digital platforms and contents are managed as strategic resources for market analysis, empowering customers to contribute and receive feedback, as well as sharing their views and preferences. Hotel managers actively manage the online presence by integrating thirdparty reviews on their website and using track software to analyze reviews. Moreover, social media and apps are implemented as relation-oriented channels to join the conversation with guests on an ongoing basis, talking, listening, learning and responding to their contents integrating their needs and wants in the service interactions. This is also evident in the response strategy adopted, which focuses on extreme positive and negative reviews. The importance of extreme reviews is stressed in different studies (Lui et al., 2018). In general, customers pay more attention to extreme reviews than moderate ones because fast solutions are required. Responding to positive extreme reviews is a way to co-create the relationship with guests, recognizing their supportive comments and providing a positive online interaction (Dickinger and Lalicic, 2014). It has also an effect on prospective guests' behaviors: by signaling attention, care and appreciation of guests' reviews, hoteliers could enhance positive word-of-mouth due to the perceived higher usefulness of the responses (Deng and Ravichandran, 2016). Drawing on extreme negative reviews, hoteliers' responses play a key role in reinforcing trust with guests and reassuring future ones that the negative experience is unlikely to be repeated (Chevalier et al., 2016). The manager response becomes a public acknowledgment of the service failure issue and, at the same time, the solution to service improvement. Then, guests decide from the response whether the management team solved the problem at a satisfactory level. In this case, the managers' responses provide additional context to other potential guests, allowing them to read both sides of the incident. Therefore, extreme negative reviews may receive higher ratings from other prospector guests, because of real-time, compelling and rewarding service improvement. 
Communication style based on human tone, as well as detailed, personalized and authentic responses or dedicated roles in charge of online monitoring contributes to reinforce the interaction with guests (Rybalko and Seltzer, 2010). Social compensations also improve guests' morale and disposition toward the hotel (Sahin et al., 2017). Timely responding to extreme reviews, personalizing content of responses and applying social compensations reinforce experiential value exchanges, strengthening emotional bonds and reducing the cognitive distance with guests. In sum, this strategy is based on ongoing customer engagement, leading to functional, cognitive, emotional and psychological value as an outcome (Ramaswamy and Ozcan, 2016; Barile et al., 2017).

A minority of hotels (cluster 2) seemed to follow a passive approach in managing online contents, without implementing a clearly defined strategy. The passive online content responsiveness is characterized by apologizing and seeking of justification for negative service delivery. More specifically, managers try to shift the responsibility for a service failure to a third party or factors beyond the control of the hotel. However, if the negative event is due to a service delivery process, distancing from the incident reduces the guests' trust (Abramova et al., 2015). Although they recognize the importance of e-WOM to detect strengths and weaknesses, these hoteliers prefer short and standardized responses which lose in informational value and do not contribute to reduce the uncertainty perceived by guests. Corporate websites represent the most used digital channel managed as a push channel both to deliver the service offering (i.e. booking, tidiness, restaurant, location, sport facilities, personal care amenities, etc.) and to communicate deals and promotions. In addition, general roles of hotel are involved in the responding activity carried out on weekly basis. In sum, these hoteliers are unaware that strategically managing UCG could improve their success. Probably, this is due to the smallest size of hotels aggregated in this cluster coupled with a lack of cultural readiness and a poor leadership.

\section{Theoretical and managerial implications}

The need for tourism and hospitality businesses to deeply understand and systematically exploit customers' contents has been intensified by the wide-ranging impact of word-ofmouth and the practice of sharing it online as results of the technological progress. Despite that, a full integration of UGC - especially e-WOM - in Italian hoteliers' digital business strategy has not yet been achieved. Anyway, our results yield important and interesting insights for theory and practice.

The first contribution of this study to the literature concerns the analysis on how e-WOM represents a valuable resource that needs to be integrated and managed at a strategic level. By adopting a holistic approach, antecedents and consequences on UGC management have been addressed, a question that previous research left open in the online reviews context (Confente, 2015; Baka, 2016). In terms of antecedents, the findings confirm ICTs pervasiveness to improve digital connectivity; besides, critical dimensions are related both to actively management and closely monitoring, be it hotel's own postings, third-party comments or reviews. These results confirm El-Gohary's (2012) claim according to which internal factors like skills, resources, culture and leadership play an important role to use information systems in digital marketing.

In terms of practical consequences, being organizationally ready to manage e-WOM is more difficult in lower star category (up to 3 stars) and independent hotels where the resources, processes and digital capabilities of people are scant in place. Probably, skill gaps, lack of dedicated personnel and organizational issues hinder a shared digitized culture that spans its effects at strategic and tactic levels (Konstantopoulou et al., 2019). Having a different mindset toward IT coupled with an open-mindedness to innovation, a more careful orchestration of digital resources, processes and competencies emerges in higher-rated hotels
Online content responsiveness strategies in hospitality

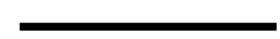


(from 4 stars up) in which different digital channels and platforms are integrated in business processes also supported by appropriate automation tools (Pacheco, 2017). Thus, a rather consistent result is that digital strategies appear to be stronger for higher-star hotels, having a more professional and sophisticated, and thus more influential, digital marketing strategy, which leads to a greater impact of tactics on online reviews (i.e. responding to guest reviews within $24 \mathrm{~h}$, tailoring content of responses, applying social compensations, etc.). All of this is despite this category being independent, that is, in percentage higher than hotel chains. This leads to the second contribution to literature. In particular, extending the findings of previous studies (Kim et al., 2015), digital business strategies are affected not only by the frequency of using information retrieved by commercial review sites and by integrating third-party review sites' reviews on hotel website, but mostly by social media channels (Moliner-Velázquez et al., 2019). What is more, the speed of the response to guests' comments seems to matter, thus confirming previous findings (Xie et al., 2017; Sparks et al., 2016; Levy et al., 2013). Last but not least, the valence of online reviews takes a more strategic value with respect to volume.

The study results let us advance some expost research propositions that can pave the way for advancements in what we currently know about UGC in the hotel management context. First, the integration of UGC in hotels business operations requires interoperable and interchangeable ICT infrastructures. By implementing interconnected information systems designed to capture and monitor a huge amount of data, hotel managers are equipped to collect, scan and interpret contextual information and provide real-time services. This implies tracking data across both multiple travel channels to understand customers' cross-channel behavior and mobile devices to enhance customer insight accurately. The difficult task is filtering and handling data in order to extract useful information. Data analysis should be supported by the development of the appropriate analysis (i.e. sentiment analysis, machine learning techniques, etc.) and methodological skills, as well as by the managerial ability to catch innovative features from data. Then we propose:

P1. Hotel managers should leverage customer knowledge, enhancing their technological and managerial big data analytics capabilities in order to optimize service delivery.

Second, the ability to foster high-quality online data analysis, coupled with the proactively monitoring through constantly listening, learning and adapting to guests' feedback, leads hotel businesses to empower customers to share their views, preferences and values. Accordingly, we propose:

P2. A data-driven strategy allows hotel businesses to enhance responsiveness to UGC management transforming them in valuable intangible assets.

Third, responding to guests' reviews, tailoring and personalizing the content of responses and timely solving their issues imply emotional interactions, providing extra value to customers and spontaneously engaging them in e-WOM. Then we propose:

P3. Facing intense competition focused and actionable response strategies is a critical competitive lever of differentiation for hotel businesses sustaining a service competitive advantage.

\section{Conclusions}

The study aimed at exploring the role of online content management in hoteliers by surveying a sample of Italian hotels and analyzing their online responsiveness. In general, it intended to contribute to the literature on e-WOM and, in particular, to the under-researched area of e-WOM management, in order to improve its benefits and mitigate its drawbacks for tourism and hospitality organizations. 
The study findings emphasized the importance of online responsiveness as an empowerment and enabling strategy. The spread of digital channels and UGC in the form of e-WOM defines new insights and possibilities for tourism and hospitality businesses to enhance their competitiveness and regain customer loyalty (Lam and Law, 2019). Accordingly, digital business strategies are necessary to leverage technology and data and innovate rebuilding customers' interactions. UGC has intrinsic business value. On the one hand, it reflects in detail the customers' service experience and perceptions, spanning information and knowledge in many-to-many interactions. On the other hand, it is able to foster loyalty of customers and influence future booking decisions. From this standpoint, hoteliers should see UGC as an important asset for value co-creation, paving the way for open innovation in their accommodation businesses.

Hotel managers need to actively manage online presence in various reviews sites, and above all, to nurture interactive communications to capture new forms of knowledge in order to improve and innovate the value of their service offering. In this vein, hospitality organizations should provide the necessary capabilities, processes and digital platforms for the customers to procure dynamic feedback and share their information. Digital contents open new opportunities for value co-creation from the ability of interacting with customers and providing adaptive and timely solutions. This would allow functional, cognitive, emotional and psychological outcomes to be achieved. However, to be successful, quick responses to complaints that allow highly personalized service are needed (Buhalis and Sinatra, 2019). More specifically, organizational agility and a creative, data-oriented and realtime mindset are the organizational enablers of online responsiveness, finally shaping a smart hospitality ecosystem (Sanchez-Franco et al., 2019).

The results of this study should be considered with the following limitations that suggest the need for future investigations in this field. Firstly, data were collected from the Italian hospitality industry, and consequently, the results may be generalizable only to that population. Future research should be conducted within different geographical contexts, and the results obtained should be carefully compared. Secondly, hotel size was not included among the variables for clustering due to the research objectives. In detail, this paper aimed to understand how hotels integrate UGC in their business and how they manage e-WOM. Thus, the focus was on hotel category variable (i.e. star rating) in line with the research stream according to which the number of stars of a hotel operationalizes the overall quality level of hotel service (Banerjee and Chua, 2016; De Pelsmacker et al., 2018) and categorizes hotels hierarchically (Kim et al., 2015). Anyway, research findings showed that clusters 1 and 2 include mainly hotels up to 3 stars. Hence, future studies should investigate the influence of hotel size, analyzed in terms of number of employees and turnover, on the use and management of e-WOM by hoteliers. Thirdly, another limitation of this research is related to the data collection technique: a survey was used to detect the perception of managers about their managerial use of UGC in the digital scenario. This perception may be biased due to the social desirability effect, that is, the tendency of respondents to answer the question overreporting the capability or under-reporting the lack of such a capability, so that they will be viewed favorably by interviewers. Further developments are required to focus on direct content analysis of hotels' responses to online reviews.

\section{Note}

1. i) Familiarity with Internet, social networks and online travel agencies;

ii) Hotel uses UGC to obtain information for market research, accessing information about customers' opinions, feelings, intentions and/or consumption behavior;
Online content responsiveness strategies in hospitality 
iii) E-WOM has a negative consideration because most online reviews are not reliable; thus, it is not prudent making review-based decisions;

iv) Effect of responding is the mitigation of potential damage caused by disservice because dissatisfied guest feels understood and taken care by hotel.

\section{References}

Abdi, H. (2003), Factor Rotations in Factor Analyses. Encyclopedia for Research Methods for the Social Sciences, Sage, Thousand Oaks, CA.

Abramova, O., Shavanova, T., Fuhrer, A., Krasnova, H. and Buxmann, P. (2015), "Understanding the sharing Economy: the role of response to negative reviews in the peer-to-peer accommodation sharing network", ECIS 2015 Completed Research Papers, Paper 1, ISBN 978-3-00-050284-2.

Aluri, A., Slevitch, L. and Larzelere, R. (2016), "The influence of embedded social media channels on travelers' gratifications, satisfaction, and purchase intentions", Cornell Hospitality Quarterly, Vol. 57 No. 3, pp. 250-267.

Assimakopoulos, C., Papaioannou, E., Sarmaniotis, C. and Georgiadis, C.K. (2014), "Online reviews as a feedback mechanism for hotel CRM systems", Anatolia: An International Journal of Tourism and Hospitality Research, Vol. 26 No. 1, pp. 5-20.

Aureli, S. and Supino, E. (2017), "Online reputation monitoring: an exploratory study on Italian hotel managers' practices”, International Journal of Hospitality and Tourism Administration, Vol. 18 No. 1, pp. 84-109.

Baka, V. (2016), "The becoming of user generated reviews: looking at the pastto understand the future of managing reputation in the travel sector", Tourism Management, Vol. 53 No. 1, pp. 148-162.

Banerjee, S. and Chua, A.Y.K. (2016), "In search of patterns among travelers' hotel ratings in TripAdvisor”, Tourism Management, Vol. 53, pp. 125-131.

Barile, S., Ciasullo, M.V., Troisi, O. and Sarno, D. (2017), "The role of technology and institutions in tourism service ecosystems: findings from a case study", The TQM Journal, Vol. 29 No. 6, pp. 811-833.

Bore, I., Rutherford, C., Glasgow, S., Taheri, B. and Antony, J. (2017), "A systematic literature review on eWOM in the hotel industry: current trends and suggestions for future research", Hospitality and Society, Vol. 7 No. 1, pp. 63-85.

Bressler, H. (2007), "Managing hotel guest complaints on user-generated travel website", COM Marketing, available at: http://ezinearticles.com/?Managing-Hotel-Guest-Complaintson-UserGenerated-Travel-Websitesandid $=520288$.

Burgess, S., Sellitto, C., Cox, C. and Buultjens, J. (2015), "Strategies for adopting consumer-generated media in small-sized to medium-sized tourism enterprises", International Journal of Tourism Research, Vol. 17 No. 5, pp. 432-441.

Buhalis, D. and Sinarta, Y. (2019), "Real-time co-creation and nowness service: lessons from tourism and hospitality", Journal of Travel and Tourism Marketing, Vol. 36 No. 5, pp. 563-582.

Calinski, T. and Harabasz, J. (1974), "A dendrite method for cluster analysis", Communications in Statistics, Vol. 3, pp. 1-27.

Cantallops, S.A. and Salvi, F. (2014), "New consumer behavior: a research on e-Wom and hotels", International Journal of Hospitality Management, Vol. 36, pp. 41-51.

Casaló, L.V., Flavián, C., Guinaliu, M. and Ekinci, Y. (2015), "Do online hotel rating schemes influence booking behaviors?", International Journal of Hospitality Management, Vol. 49, pp. 28-36.

Cattell, R.B. (1965), "A biometrics invited paper. factor analysis: an introduction to essentials I. The purpose and underlying models", Biometrics, Vol. 21 No. 1, pp. 190-215. 
Chevalier, J.A., Dover, Y. and Mayzlin, D. (2016), "Channels of Impact: user reviews when quality is dynamic and managers respond", available at: https://ssrn.com/ abstract1/42766873.

Christodoulides, G., Michaelidou, N. and Argyriou, E. (2012), "Cross-national differences in e-WOM influence", European Journal of Marketing, Nos 11-12, pp. 1689-1707.

Confente, I. (2015), "Twenty-five years of Word-of-Mouth studies: a critical review of tourism research", International Journal of Tourism Research, Vol. 17 No. 6, pp. 613-624.

Crijns, H., Cauberghe, V., Hudders, L. and Claeys, A.S. (2017), "How to deal with online consumer comments during a crisis? The impact of personalized organizational responses on organizational reputation”, Computers in Human Behavior, Vol. 75, pp. 619-631.

Crotts, J.C., Mason, P.R. and Davis, B. (2009), "Measuring guest satisfaction and competitive position in the hospitality and tourism industry”, Journal of Travel Research, Vol. 48 No. 2, pp. 139-151.

De Pelsmacker, P., van Tilburg, S. and Holthof, C. (2018), "Digital marketing strategies, online reviews and hotel performance", International Journal of Hospitality Management, Vol. 72, pp. 47-55.

Deng, C. and Ravichandran, T. (2016), "Managieral response to online compliments: helpful or harmful?", Thirty Seventh International Conference on Information Systems, Dublin, pp. 1-10.

Dickinger, A. and Lalicic, L. (2014), "How emotional do we get? a closer look into the trip advisor dialogue", in Xiang, Z. and Tussyadiah, I. (Eds), Information and Communication Technologies in Tourism, Springer International Publishing, Cham, pp. 239-252.

Dillman, D.A. (2011), Mail and Internet Surveys: The Tailored Design Method-2007 Update with New Internet, Visual, and Mixed-Mode Guide, John Wiley and Sons, Hoboken, NJ.

Draisma, S. and Dijkstra, W. (2004), "Response latency and (para) linguistic expressions as indicators of response error", Methods For Testing and Evaluating Survey Questionnaires, p. 131147.

Duverger, P. (2013), "Curvilinear effects of user-generated content on hotels' marketshare: a dynamic panel-data analysis", Journal of Travel Research, Vol. 52 No. 4, pp. 465-478.

El-Gohary, H. (2012), "Factors affecting E-Marketing adoption and implementation in tourism firms: an empirical investigation of Egyptian small tourism organizations", Tourism Management, Vol. 33 No. 5, pp. 1256-1269.

Eurostat (2017), "E-commerce statistics for individuals", available at: http://ec.europa, eu/eurostat/ statistics-explained/index.php/E-commerce_statistics_for_individuals.

Flanagin, A.J. and Metzger, M.J. (2013), "Trusting expert-versus user-generated ratings online: the role of information volume, valence, and consumer characteristics", Computers in Human Behavior, Vol. 29 No. 4, pp. 1626-1634.

$\mathrm{Gu}, \mathrm{B}$. and Ye, Q. (2014), "First step in social media: measuring the influence of online management responses on customer satisfaction", Production and Operations Management, Vol. 23 No. 4, pp. 570-582.

Hair, J.F., Anderson, R.E., Tatham, R.L. and Black, W.C. (1998), Multivariate Data Analysis, Englewood Cliff, NJ, Vol. 5 No. 3, pp. 207-2019.

Horn, J.L. (1965), “A rationale and test for the number of factors in factor analysis", Psychometrica, Vol. 30, pp. 179-185.

Hu, Y. and Kim, H.J. (2018), "Positive and negative e-wom motivations and hotel customers' e-wom behavior: does personality matter?", International Journal of Hospitality Management, Vol. 75, pp. 27-37.

Kaiser, H.F. (1970), “A second generation Little Jiffy”, Psychometrika, Vol. 35, pp. 401-415.

Kerlinger, F.N. (1986), Foundations of Behavioral Research, Holt, Rinehart and Winston, New York, NY.

Kim, E.E.K., Mattila, A.S. and Baloglu, S. (2011), "Effects of gender and expertise on consumers' motivation to read online hotel reviews", Cornell Hospitality Quarterly, Vol. 52 No. 4, pp. 399-406. 
Kim, W.G., Lim, H. and Brymer, R.A. (2015), "The effectiveness of managing social media on hotel performance", International Journal of Hospitality Management, Vol. 44, pp. 165-171.

Konstantopoulou, A., Rizomyliotis, I., Konstantoulaki, K. and Badahdah, R. (2019), 'Improving SMEs' competitiveness with the use of Instagram influencer advertising and eWOM", International Journal of Organizational Analysis, Vol. 27 No. 2, pp. 308-321.

Kwok, L., Xie, K. and Tori, R. (2017), "Thematic framework of online review research: A systematic analysis of contemporary literature on seven major hospitality andtourism journals", International Journal of Contemporary Hospitality Management, Vol. 29 No. 1, pp. 307-354.

Lam, C. and Law, R. (2019), "Readiness of upscale and luxury-branded hotels for digital transformation”, International Journal of Hospitality Management, Vol. 79, pp. 60-69.

Lanz, L., Fischhof, B. and Lee, R. (2010), "How are hotels embracing social media in 2010? Examples of how to start engaging", HVS Sales and Marketing Services, available at: www.hvs.com/ staticcontent/library/nyu2010/Journal/Articles/SocialMediaIn2010.pdf.

Lattin, J., Carroll, J.D. and Green, P.E. (2003), Analysing Multivariate Data, Thomson Learning, London.

Lavrakas, P.J. (2008), Encyclopedia of Survey Research Methods, Sage Publications, Thousand Oaks, CA.

Lee, C.H. and Cranage, D.A. (2014), "Toward understanding consumer processing of negative online word-of-mouth communication: the roles of opinion consensus and organizational response strategies", Journal of Hospitality and Tourism Research, Vol. 38 No. 3, pp. 330-360.

Lee, Y.L. and Song, S. (2010), "An empirical investigation of electronic word-of-mouth: informational motive and corporate response strategy", Computers in Human Behavior, Vol. 26 No. 5, pp. 1073-1080.

Levy, S., Duan, W. and Boo, S. (2013), "An analysis of one-star online reviews and responses in the Washington, D.C., lodging market”, Cornell Hospitality Quarterly, Vol. 54 No. 1, pp. 49-63.

Li, C., Cui, G. and Peng, L. (2017), "The signaling effect of management response in engaging customers: a study of the hotel industry", Tourism Management, Vol. 62, pp. 42-53.

Li, C., Cui, G. and Peng, L. (2018), "Tailoring management response to negative reviews: the effectiveness of accommodative versus defensive responses", Computers in Human Behavior, Vol. 84, pp. 272-284.

Liang, S., Ekinci, Y., Occhiocupo, N. and Whyatt, G. (2013), “Antecedents of travellers' electronic wordof-mouth communication", Journal of Marketing Management, Vol. 29 Nos 5-6, pp. 584-606.

Litvin, S.W., Goldsmith, R.E. and Pan, B. (2008), "Electronic word-of-mouth in hospitality and tourism management”, Tourism Management, Vol. 29, pp. 458-468.

Liu, X., Schuckert, M. and Law, R. (2015), "Can response management benefit hotels? evidence from Hong Kong hotels", Journal of Travel and Tourism Marketing, Vol. 32, pp. 1069-1080.

Lui, T.W., Bartosiak, M., Piccoli, G. and Sadhya, V. (2018), "Online review response strategy and its effects on competitive performance", Tourism Management, Vol. 67, pp. 180-190.

Min, H., Lim., Y. and Magnini, V.P. (2015), "Factors affecting customer satisfaction in responses to negative online hotel reviews: the impact of empathy, paraphrasing, and speed", Cornell Hospitality Quarterly, Vol. 56 No. 2, pp. 223-231.

Moliner-Velázquez, B., Fuentes-Blasco, M. and Gil-Saura, I. (2019), "The role of ICT, eWOM and guest characteristics in loyalty", Journal of Hospitality and Tourism Technology, Vol. 10 No. 2, pp. 153-168.

Nguyen, K.A. and Coudounaris, D.N. (2015), "The mechanism of online review management: a qualitative study", Tourism Management Perspectives, Vol. 16, pp. 163-175.

Noone, B.M., McGuire, K.A. and Rohlfs, K.V. (2011), "Social media meets hotel revenue management: opportunities, issues and unanswered questions", Journal of Revenue and Pricing Management, Vol. 10 No. 4, pp. 293-305. 
Nusair, K., Parsa, H.G. and Cobanoglu, C. (2011), "Building a model of commitment forGeneration Y: an empirical study on e-travel retailers", Tourism Management, Vol. 32, pp. 833-843.

Osborne, J.W., Costello, A.B. and Kellow, J.T. (2008), "Best practices in exploratory factor analysis", in Osborne, J.W. (Eds), Best Practices in Quantitative Methods, Sage, Thousand Oaks, CA, pp. 86-99.

Pacheco, L. (2017), "Customer satisfaction in Portuguese hotels: evidence for different regions and hotel segments", Tourism Analysis, Vol. 22 No. 3, pp. 337-347.

Phillips, P., Barnes, S., Zigan, K. and Schegg, R. (2017), "Understanding the impact of online reviews on hotel performance: an empirical analysis", Journal of Travel Research, Vol. 56 No. 2, pp. 235-249.

Pühringer, S. and Taylor, A. (2008), "A practitioner's report on blogs as a potential source of destination marketing intelligence”, Journal of Vacation Marketing, Vol. 14 No. 2, pp. 177-187.

Raguseo, E. and Vitari, C. (2017), "The effect of brand on the impact of e-WOM on hotels' financial performance", International Journal of Electronic Commerce, Vol. 21 No. 2, pp. 249-269.

Ramaswamy, V. and Ozcan, K. (2016), "Brand value co-creation in a digitalized world: an integrative framework and research implications", International Journal of Research in Marketing, Vol. 33 No. 1, pp. 93-106.

Rose, M. and Blodgett, J.G. (2016), "Should hotel respond to negative online reviews?", Cornell Hospitality Quarterly, Vol. 57 No. 4, pp. 396-410.

Rybalko, S. and Seltzer, T. (2010), "Dialogic communication in 140 characters or less", Public Relations Review, Vol. 36 No. 4, pp. 336-341.

Sahin, I., Gulmez, M. and Kitapci, O. (2017), "E complaint tracking and online problem-solving strategies in hospitality management", Journal of Hospitality and Tourism Technology, Vol. 8 No. 3, pp. 372-394.

Sanchez-Franco, M., Cepeda-Carrion, G. and Roldán, J. (2019), "Understanding relationship quality in hospitality services: a study based on text analytics and partial least squares", Internet Research, Vol. 29 No. 3, pp. 478-503.

Schuckert, M., Liu, X. and Law, R. (2015), "Hospitality and tourism online reviews: recent trends and future directions", Journal of Travel \& Tourism Marketing, Vol. 32 No. 5, pp. 608-621.

Sharma, S. (1996), Applied Multivariate Techniques, John Wiley and Sons, New York, NY.

Sigala, M., Christou, E. and Gretzel, U. (2012), Social Media in Travel, Tourism and Hospitality: Theory, Practices and Cases, Ashgate Publishing Limited, Surrey.

Sparks, B.A. and Bradley, G.L. (2017), "A 'Triple A' typology of responding to negative consumergenerated online reviews", Journal of Hospitality and Tourism Research, Vol. 41 No. 6, pp. 719-745.

Sparks, B.A. and Browning, V. (2011), "The impact of online reviews on hotel booking intentions and perception of trust", Tourism Management, Vol. 32, pp. 1310-1323.

Sparks, B.A., So, K.K.F. and Bradley, G.L. (2016), "Responding to negative online reviews: the effects of hotel responses on customer inferences of trust and concern", Tourism Management, Vol. 53, pp. 74-85.

Sun, L.B. and Qu, H. (2011), "Is there any gender effect on the relationship between service quality and word-of-mouth?", Journal of Travel and Tourism Marketing, Vol. 28 No. 2, pp. 210-224.

Tabachnick, B.G., Fidell, L.S. and Ullman, J.B. (2007), Using Multivariate Statistics, Pearson, Boston, MA,Vol. 5.

Tsao, W.C., Hsieh, M.T., Shih, L.W. and Lin, T.M. (2015), "Compliance withe-wom: the influence of hotel reviews on booking intention from the perspective of consu mer conformity", International Journal of Hospitality Management, Vol. 46, pp. 99-111.
Online content responsiveness strategies in hospitality

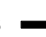

(1)


Van Laer, T. and de Ruyter, K. (2010), "In stories we trust: how narrative apologies provide cover for competitive vulnerability after integrity-violating blog posts Intern", Journal of Research in Marketing, Vol. 27, pp. 164-174.

Viglia, G. and Buhalis, D. (2016), "The influence of e-word-of-mouth on hoteloccupancy rate", International Journal of Contemporary Hospitality Management, Vol. 28 No. 9, pp. 2035-2051.

WTTC (2018), Travel and Tourism, Economic Impact 2018, World Travel and Tourism Council, Italy London.

Xie, H.J., Miao, L., Kuo, P. and Lee, B. (2011), "Consumers' responses to ambivalentonline hotel reviews: the role of perceived source credibility and predecisionaldisposition", International Journal of Hospitality Management, Vol. 30, pp. 178-183.

Xie, K.L., Zhang, Z. and Zhang, Z. (2014), "The business value of online consumer reviews and management response to hotel performance", International Journal of Hospitality Management, Vol. 43, pp. 1-12.

Xie, K.L., So, K. and Wang, W. (2017), "Joint effects of management responses and online reviews on hotel financial performance: a data-analytics approach", International Journal of Hospitality Management, Vol. 62, pp. 101-110.

$\mathrm{Xu}, \mathrm{X}$. and Li, Y. (2015), "The antecedents of customer satisfaction and dissatisfaction toward various types of hotels: a text mining approach", International Journal of Hospitality Management, Vol. 55, pp. 57-69.

Ye, Q., Law, R. and Gu, B. (2009), "The impact of online user reviews on hotel room sales", International Journal of Hospitality Management, Vol. 28 No. 1, pp. 180-182.

Yong, A.G. and Pearce, S. (2013), “A beginner's guide to factor analysis: focusing on exploratory factor analysis", Tutorials in Quantitative Methods for Psychology, Vol. 9 No. 2, pp. 79-94.

Yoo, K.H. and Gretzel, U. (2011), "Influence of personality on travel-related consumer-generated media creation", Computers in Human Behavior, Vol. 27 No. 2, pp. 609-621.

You, Y., Vadakkepatt, G.G. and Joshi, A.M. (2015), "A meta-analysis of electronic word-of-mouth elasticity”, Journal of Marketing, Vol. 79 No. 2, pp. 19-39.

Zwick, W.R. and Velicer, W.F. (1986), "Comparison of five rules for determining the number of components to retain", Psychological Bulletin, Vol. 99 No. 3, pp. 432-442.

\section{Further reading}

Brodie, R.J., Hollebeek, L.D. and Conduit, J. (2015), Customer Engagement: Contemporary Issues and Challenges, Routledge, Oxon.

Bronner, F. and Hoog, R. (2011), "Vacationers and e-WOM: who posts, and why, where, and what?", Journal of Travel Research, Vol. 50 No. 1, pp. 15-26.

Loureiro, S.M.C. and Kastenholz, E. (2011), "Corporate reputation, satisfaction, delight, and loyalty towards rural lodging units in Portugal", International Journal of Hospitality Management, Vol. 30 No. 3, pp. 575-583.

Park, S.Y. and Allen, J.P. (2013), "Responding to online reviews: problem solving and engagement in hotels", Cornell Hospitality Quarterly, Vol. 54 No. 1, pp. 64-73.

Phillips, P., Zigan, K., Silva, M.M.S. and Schegg, R. (2015), "The interactive effects of online reviews on the determinants of Swiss hotel performance: a neural network analysis", Tourism Management, Vol. 50, pp. 130-141.

\section{Corresponding author}

Maria Vincenza Ciasullo can be contacted at: mciasullo@unisa.it 


\section{Appendix}

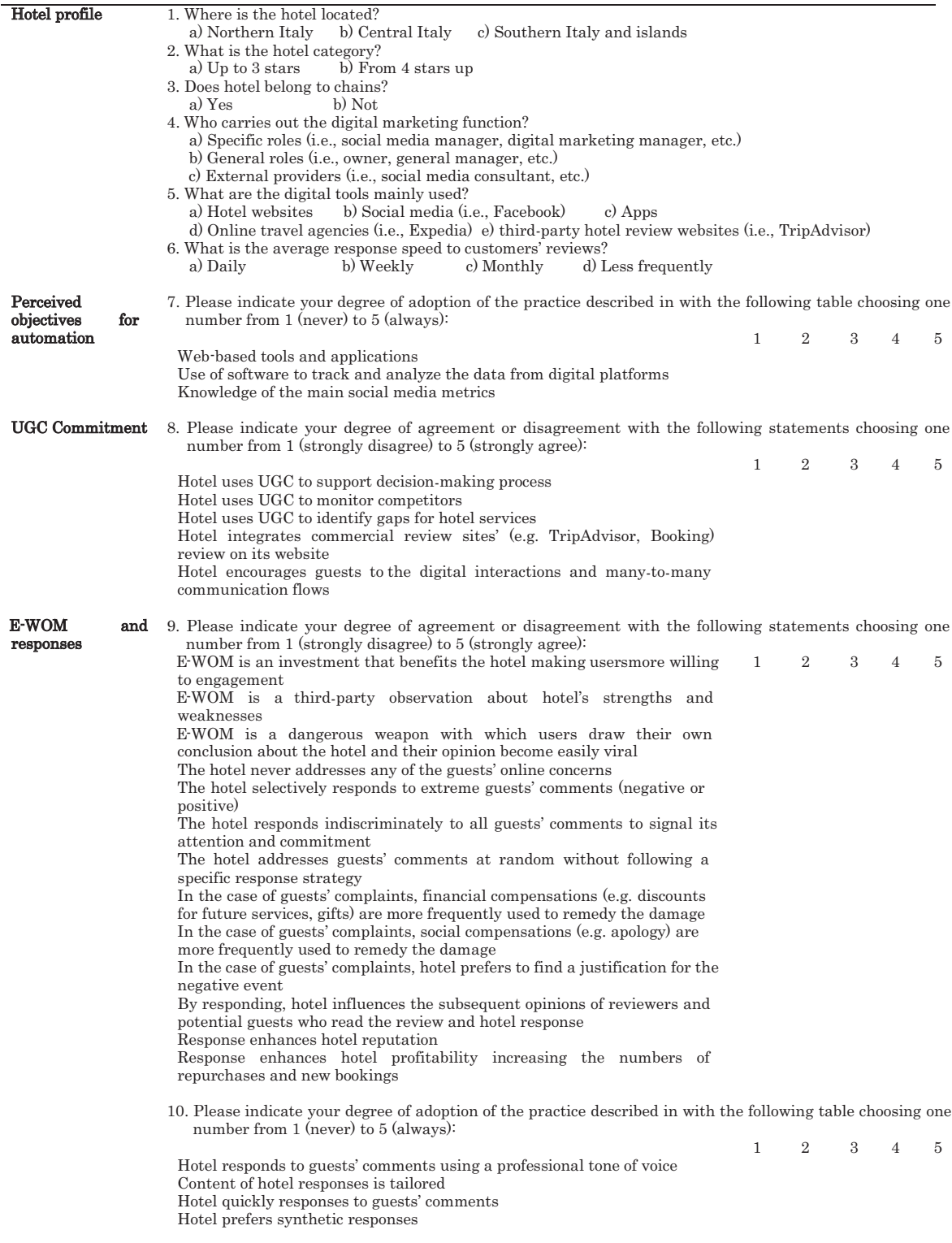

